\title{
Design and Development of an Earthquake Warning System Module using Electronic Sensor for Tilt Identification and Low Frequency Sensing Analysis
}

\section{Pushan Kumar Dutta}

\author{
Erasmus Mundus Leaders Post-Doctoral Research Scholar, University of Oradea, Romania \\ Asst. Professor, Electronics and Communication Engineering, RGMCET, Andhra Pradesh, India \\ pkdgeoindia@gmail.com
}

\begin{abstract}
The proposed work involves identification of a filter that can identify strong earthquakes characterized by lower frequencies than medium size earthquakes, are able to excite longest periods and amplify deep sediments enhancing both duration and amplitude. When the water level tilts, the hardware device immediately activates the circuit designed in Multisim. The circuit design uses readily available electronic components including a LM324N op-amp and a NE-555 timer circuit able to detect electrical and environmental characteristics and is capable to analyze low frequency components that are equivalent to movements incorporated as a result of this tilt to respond with the alarm using negative impedance characteristics. One major limitation of geophones is the electrical damping. We applied a shunt resistor using back electromotive force which acts as damping. The maximum electrical damping is limited by the value of the passive resistor. We present the general architecture of the circuit with description and operation, design flow chart and implementation of the sensor.
\end{abstract}

Keywords: Sensor, Electronic Control Module, Earthquake Warning, Radon Monitoring Unit

\section{INTRODUCTION}

Despite all the scientific advances in the field of earthquake prediction, the idea of accurate prediction and monitoring of earthquakes still remains a vision of the future.Although many techniques have been implemented and the avenues of scientific warning based on interdisciplinary analysis of electronic instrumentation, geophysical explanation and a consistent time margin between a potential warning and its eventuality remains a dream for scientists around the world; there is also a need to simultaneously get rid of any possibility of erroneous detections leading to false alarms associated with the different earthquake patterns and associated stress-strain interactions between the geophysical parameters and precursors. In order to extend the scope of analysis of the temporal and spatial evolution of stress in the different stages of the fault system associated with the complexity of the fault geometry, heterogeneity, and anisotropy of the rock for the host rock media exhibiting highly variable behavior in the incipient region (Schulz e al., 1973; Srivastava, 1983) so that a plausible earthquake early warning system can be developed for earthquake risk mitigation for the region. There are three basic reasons we feel that earthquake prediction analysis has suffered due to the absence of reliable diagnostic precursors for different geo-tectonic settings responsible for earthquake genesis. Existing Earthquake Warning Systems (EWS) are often based on a deterministic approach which led to many false alarms after the strong faulting segments accumulate strain to become areas of instability (Dutta et al., 2012 a,b). Secondly, sudden occurrence of earthquakes and their incipient source showing precursory behavioral patterns (Dutta et al., 2013a) occurring in different parts of the world were associated with smaller response time that pre-detect a certain cluster of earthquake patterns (Dutta et al., 2012c). Thirdly, adoption of available earthquake resistant building codes assimilated up to a particular size of earthquake by several earthquake prone countries is also not apt to ensure reduced degree of earthquake hazards to infrastructures and vital structures located in seismically active regions. These constraints are prevailed because the process of earthquake 
Design and Development of an Earthquake Warning System Module using Electronic Sensor for Tilt Identification and Low Frequency Sensing Analysis

genesis is found to be dynamic and the generating mechanism remains completely uncertain in terms of size and its depth of occurrence (Mishra, 2007). Figure 1 shows the structural frame of the electronic detection device with its operating principles. Passive seismological parameters identified using GPS sensors and strain meters associated are found to occur at very low frequencies explicitly identified as a data count(Dutta, 2017). It becomes increasingly difficult to maintain an inertial reference, and for the observation of low-order free oscillations of the Earth, tidal motions, and quasi-static deformations as strainmeters may outperform inertial seismometers. Strainmeters are conceptually simpler than inertial seismometers although their technical realization and installation may be more difficult. It is thus a necessity to design a conceptual hardware module that can sense and detect over a period of time, the passive components like tilt or strain on the surface using volumetric analysis of precursory parameters generated during a continuous tectonic movement and provide onsite alarm system.

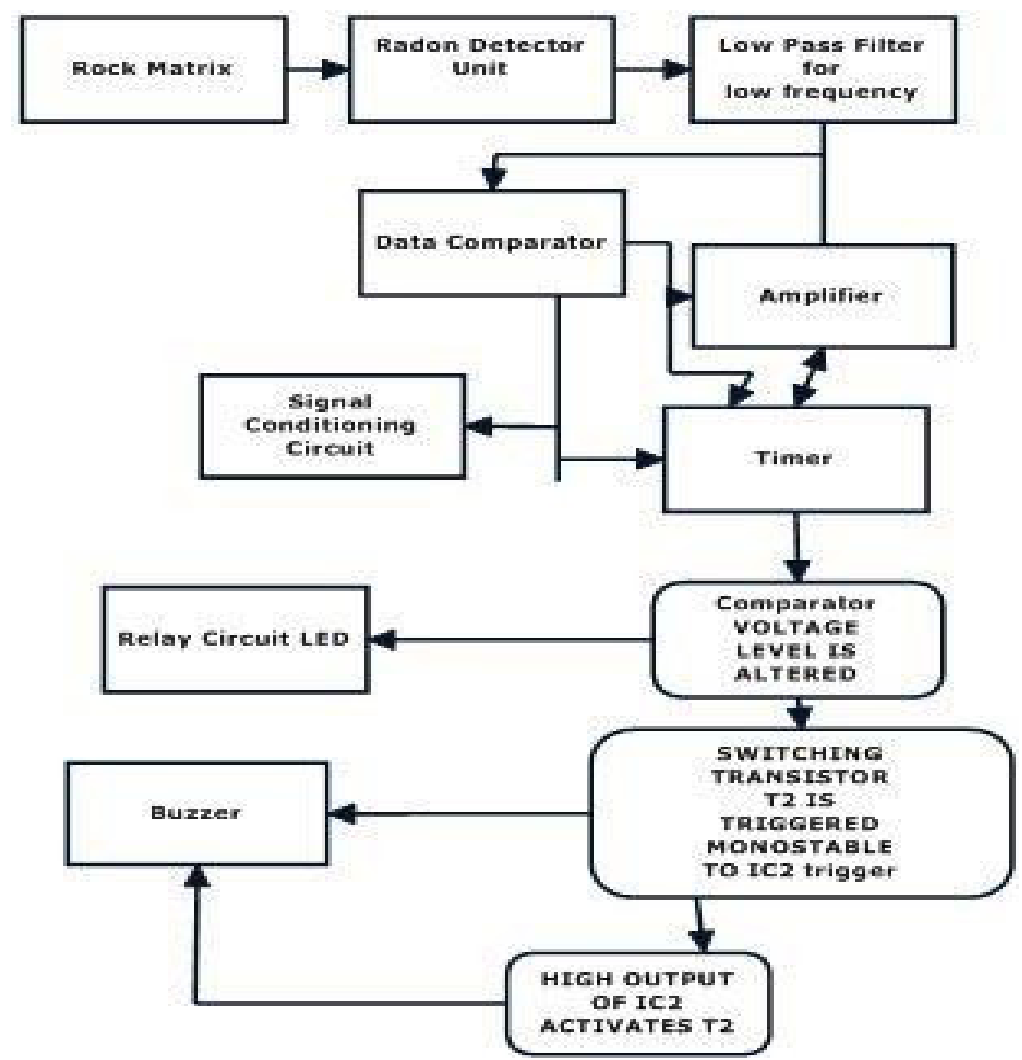

Fig1. Structural Frame of the Electronic Device Developed

The aim of this electronic device is to acquire data in the form of tilt and radon count and acts like a passive method of detection. The electronic device is aimed at sensing and detecting the change of the level of water absorbed in a Radon detection unit. The instrument designed has been developed based on the concept that the geological rock medium is a collection of arrays of rock matrix undergoing stress-related deformation at different depths. The difference of conditions of measurements of soil radon in these cases results in some data registration in the form of radon count in Volumetric Analysis of Radon (VAR). First, at such mode of selection of soil gas we deal not with true value VAR in the given point of measurement, but with some quasi stationary values VAR which is defined(determined) as properties of the system and in parameters of a data-acquisition equipment. 
Design and Development of an Earthquake Warning System Module using Electronic Sensor for Tilt Identification and Low Frequency Sensing Analysis

Second, quasi-stationary level VAR is formed as for the account emanation of radon in seized pumping volume of rocks (depression volume), and diffusion flow of radon of a file outside depression zones. At constant parameters of environment and hardware conditions of registration level of VAR the diffusive flow is found to be stable enough and constant (Outkin et al., 2006). The radon detector unit locates the position of extension and compression zones within the rock mass based on study conducted by (Outkin et al., 2013). The tectonic movements can be interpreted by resetting elastic energy leads to earthquake after reducing signal line friction and elastic strain relief (Outkin, 2000) lithospheric blocks and are able to continue their movement in the original quasychaotic direction. Furthermore, a monitoring of soil radon in an active seismic region elucidated the VAR behavior reflecting compression and extensional stress during rock mass surface bending in connection with geodynamic processes. Based on the experiments, a new model is proposed here for the precursors to geodynamic events and their connection with radon exhalation. The passing wave in a soil layer will filtered, but this filtering process affects the high frequency part of earthquake wave more deeply. This is because of nature of soil in which the energy of higher frequencies will dissipated since the soil particles damped this frequencies by moving in their place freely Deformation resulting from strain may force the Radon out and lead to emissions of Radon that show up in well water. The newly formed micro-cracks discussed above could serve as pathways for the Radon to escape into groundwater. Preparation and realization of the tectonic events are studied on the basis of analysis of monitoring data of radon (radon activity 3-d VAR) (Chu-Yu-King, 1991; Outkin et al., 2006). Content of radon in the air about $10-16 \%$ ), so it may not, in principle, affect the behavior of the mountain massif under compression-tension, but radon is soil air and can serve as a good indicator of changes in consistency of the air and the pressure of the gaseous phase.

\section{OVERVIEW}

The lithospheric blocks remain almost without fracture, but is substantially changedconfiguration (location) units and the interblock structure. When further movement of blocks may repeat the described situation and occurrence of earthquakes in another part of the seismogenetic area. This model is verified by radon monitoring (Chu-Yu-King , 1991, Outkin e al.,2006)and allows tangible ways of prediction of tectonic earthquakes. In this study, a radon detector unit proposed by Outkin et al. (2012) shows a convective phenomenon is found to take place as the water flows along the bore-hole in response to the hydraulic gradient that occurs due to stress induced earthquake. It was used for compulsory pumping soil gas from the air-tight sealed chink by depth of 2-3 m.

\section{Sensor Model for Measumement}

The instrument is based on experience gained technique of measurements with forced hole degassing developed by (Kozlova and Yurkov, 2005) shown in Figure 2, and has the following requirements: The instrument must determine the average value of radon concentration (RC). The processed data may be completely transferred into a PC. The sensor is based on convective technique whereby soil gas is pumped out from the tube (whereby the water head pressure in the latter decreases to $20-30 \mathrm{~mm}$ ) and then flows to the instrument which measures radon concentration in the gas flux. In this case, radon influx into the rarefied space is from a much larger effective collection zone of a radius of $\sim 700 \mathrm{~mm}$. This modification increases the sensitivity of the measurements by a factor of three approximately and, at the same time, reduces the tidal and weather noise. The results of the measurements are stored in memory every hour, along with the time measurements. Minimum concentration: concentration determined with a statistical error equal to $\pm 20 \%$ : $80 \mathrm{~Bq} / \mathrm{m} 3$ for 1 hour of measurement. Maximum concentration: about $150 \mathrm{kBq} / \mathrm{m} 3$. 
Design and Development of an Earthquake Warning System Module using Electronic Sensor for Tilt Identification and Low Frequency Sensing Analysis

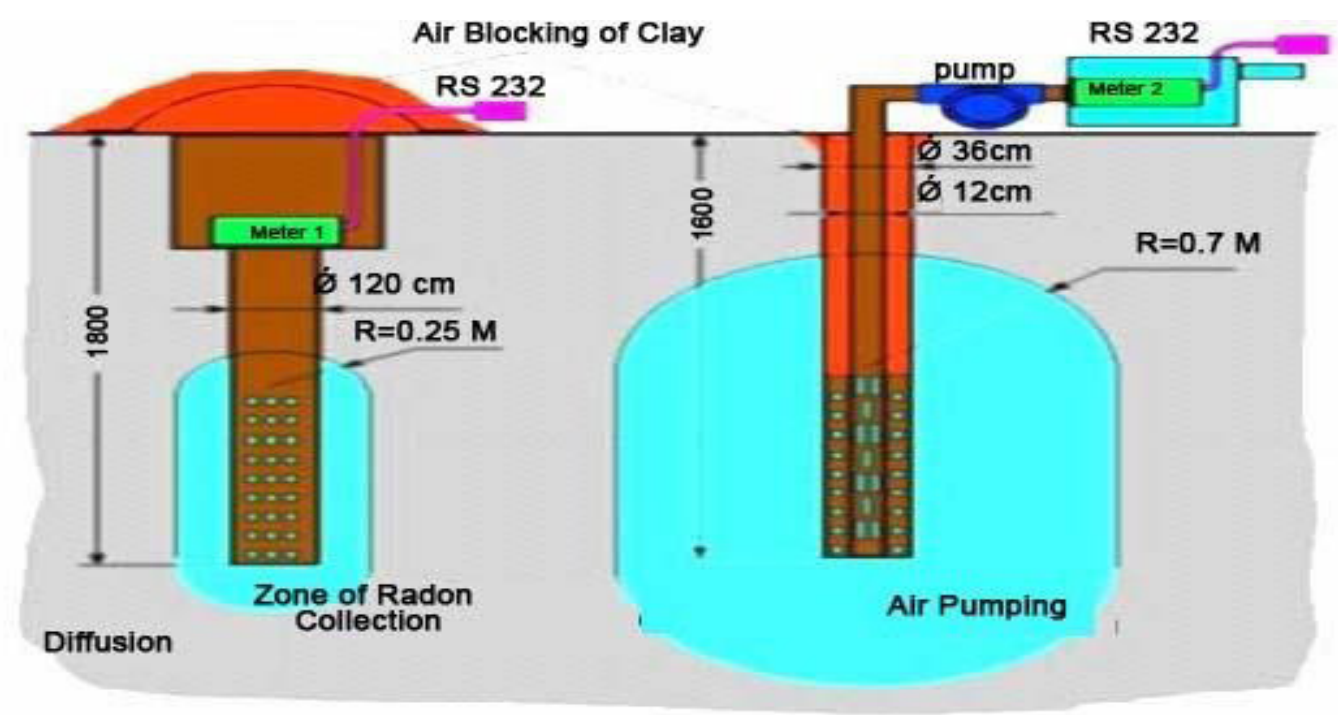

Diagram of experimental borehole

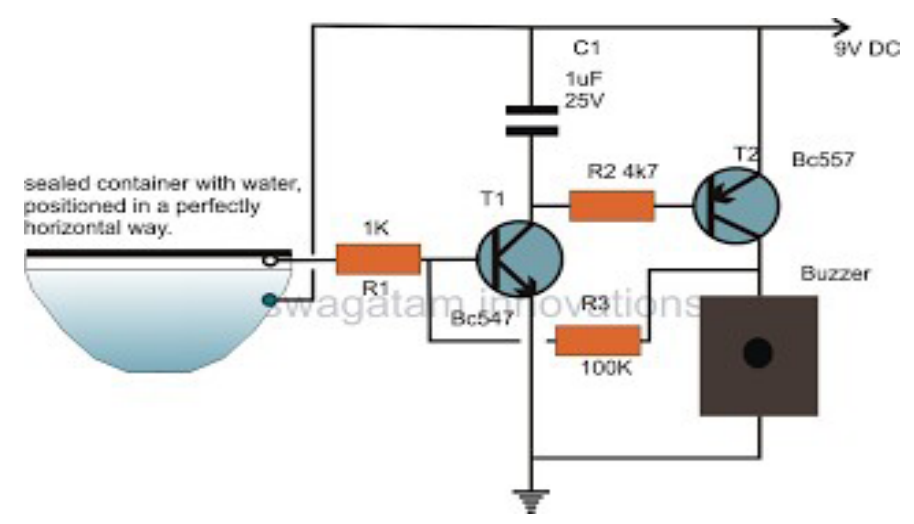

Fig2. Diagrams of the equipment which was used in experiment on Northern Tian - Shan (Outkin and Yurkov,2010;Outkin et al., 2012)

The data on VAR due to convective measurement technique yields more information about increase of speed of migration of radon in the rock fracture which increases approximately by 2-4 times of the normal showing an anomaly and increases three times the normal as observed for any detector of radon on depth about 3 meters (On Northern Tian-Shan VAR has increased almost up to $5000 \mathrm{Bk} / \mathrm{m} 3$ instead of $1500 \mathrm{Bk} / \mathrm{m} 3$ ). Second, a level of daily variations due to daily tidal movements shows that 5-7 \% from average size VAR (instead of 40-50\% in radon diffusion coefficient) is reduced. Thirdly, it is observed for deep bores, the detector influence of atmospheric pressure on data VAR is practically eliminated. In such a scenario, the SNR can be further improved by aggregating data from the right groups of cells that tend to experience the first shakings together (co-activated") accuracy of detection and localization (estimating the initial location) of geospatial events as a function of sensor and event parameters. It has been found that such geo-spatial events generate acoustic radiation (acoustic emission) which is registered as continuous noise variation in regions with high seismic activity and forms underground background sound. Formally, any disruption of solidity is an earthquake; the difference lies in place and the amount of the emitted energy. Special hoist (logging-hoist) is used in which measuring equipment is set and connected by digital communication channel with the central point of control 
Design and Development of an Earthquake Warning System Module using Electronic Sensor for Tilt Identification and Low Frequency Sensing Analysis

according to RS-232 mode. When piezoelectric ceramics are used as sensors, there is usually some noise in the measure voltage. All sensors of radon located with merged in modern radio channel (Dutta et al., 2013b) which analyzes the data obtained for defined behavior for dilatancy sizes and approximately sensors of radon (radon special sensors) located within our region of interest merged in modern radio channel with some data processing centre, which, we assume, analyzes the data obtained, inter alia, defines behavior VAR dilatancy zone (Outkin and Yurkov, 2010), their size and approximately the expected power events, as well as the position of the epicenter.

\section{Conceptual Design of Warning And Alert System}

The project work presented the design and implementation of seismic sensors using solenoid magnetic field sensors for tilt diagnostics and possibly important for earthquake research and prediction. Using Negative Impedance Converters allows extending the frequency response of small scaled coil induction sensors to the ULF range. The NIC output voltage in the case of little 'negative impedance' (Rinput $<<R L$ ) is proportional to the time derivative of the magnetic field component. Approaching the limit value R input $\rightarrow$ RL the NIC operates as an integrator and output voltage is proportional to the magnetic field component itself. At the same time sensitivity at the low frequency end is maximized. A standard piezo sensor is used to detect vibrations/sounds due to pressure changes. The piezo element acts as a small capacitor having a capacitance of a few nanofarads. Like a capacitor, it can store charge when a potential is applied to its terminals. It discharges through VR1, when it is disturbed. Piezo transducer would be solely able to sense high frequency vibrations and never a swaying action. An earthquake will never generate a shrill noise rather it produces a gentle swaying pattern, when it hits. Therefore using a piezo element is a flop idea. Of course a piezo would detect tremors only if it were used in the form of a load-cell, by integrating some kind of load, assembled for implementing an oscillating action during tremors. In the present earthquake sensor circuit, we have used radon detector unit as the detecting agent as shown in Figure 3. The mechanism works in principle in identification of change of water levels with change of the radon detection count. The multisim design of a Electronic module is shown in Figure 4. The top module has been designed by feeding pulses through an AC source that simulates the output from a radon detector counter . Like a capacitor, it can store charge when a potential is applied to its terminals. It discharges through VR1, when it is disturbed. In the circuit, IC LM324 (IC1) is wired as a differential amplifier with both its inverting and non-inverting inputs tied to the negative rail through a resistive network comprising R1, R2 and R3. Under idle conditions (as adjusted by VR1), both the inputs receive almost equal voltages, which keeps the output low. The method for predicting seismic events includes identification electronic part consists of a couple of transistors rigged into a latch circuit. The input to this circuit is achieved from a small half round container filled with water. The positive supply from the circuit is dipped inside the water while the hot end of the input is placed in such a way that it stands just a mm above the water. The detection unit fitted with current electrodes $(A, B)$ and potential probes $(M, N)$ arranged in the ground and detecting electrical current and induced potentials by means of said electrodes $(A, B)$ and said reception probes $(M, N)$, for the calculation of pressure changes in the ground. The moment the level pressure reduces by $20-30 \mathrm{~mm}$, the hot end of the circuit with the positive terminal, dipped inside the water. The positive of the supply immersed in the water instantly makes contact with the HOT end of the circuit via water; the circuit gets triggered and immediately latches. The connected buzzer sounds, sending an alarm signal. The disturbance discharges the stored charge. This causes the IC1to produce a high output. This high output is used to trigger switching transistor IC2 and the vibration or sound or movement made caused the buzzer to beep. The sound and vibration caused movements can also be detected by new and growing technology. As radon data provides the output, Q3 transistor is generally in dormant state and on detecting the water filled sensor assembly, the needles within the sensor container are subjected to a short-circuit caused by water with the availability of positive voltage at Q3's lower part triggering to get activated. Q3's activation triggers those of Q4. The next transistors stage which Q4 provides static bias 
Design and Development of an Earthquake Warning System Module using Electronic Sensor for Tilt Identification and Low Frequency Sensing Analysis

for Q3 making it to be latched with the DC output that will pass through the comparator LM324N. LM324 is a low-noise JFET input op-amp with low input bias and offset current. The BIFET technology provides fast slew rates. The reference voltage of the LM324N is fixed with the help of R2. This alters the voltage level at the inputs of comparator LM324N and the output momentarily swings high as indicated by green LED1. This high output is used to trigger switching transistor Q1, which triggers monostable IC2. Placing a low-pass RC filter at the output of the amplifier R4 C6 can help nullify the feed-through of high-frequency signals. The timing period of 555 timer is determined by R7 and C5. With the shown values, it will be around two minutes. The high output from IC2 activates Q2 and the buzzer starts beeping along with red light indication from LED2.

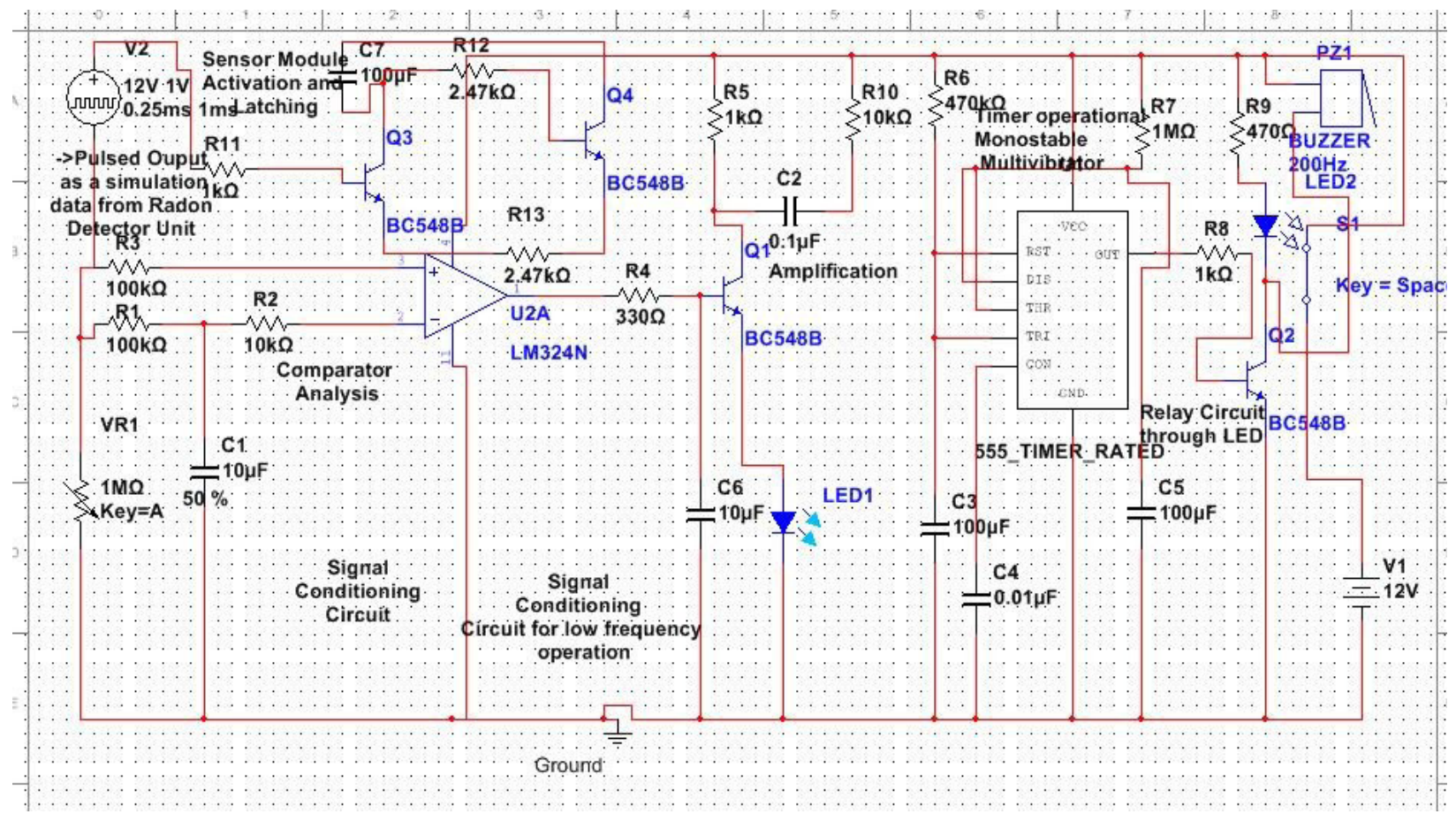

Fig4. Design of Multisim Simulation Diagram with Electronic End circuit

\section{IDENTIFICATION OF THE SENSING SEISMogenic Zone}

The study warrants "target zone" has been defined as the study area which constituted from porous cracked saturated rocks and with high capacity of cracks growth during increasing tectonic stress. In this distinctive zone, a radon monitoring measurement in soil and groundwater has been implemented (radon precursory study in soil and groundwater is quite difference in measurement methods, but not in interpretation with seismic events). This may prove costly in earthquake warning message transmission whereby a mini delay in data transfer might collapse the entire system. The natural pre-earthquake phenomena such as gravity variations, radon emanation, anomalous electric field and changes in meteorological parameters like temperature and relative humidity can be found statistically and empirical relation can be drawn in respect to a regression equation based on geo-spatial variables (Dutta et al., 2011). The concept of Earthquake Preparation Zone which is the first sign of an imminent earthquake is described. According to this concept all the ground based preearthquake signals are generated all over this zone. The size of this zone is dependent upon the size of the earthquake under preparation and may have a radius of more than $300 \mathrm{~km}$ for an earthquake of magnitude 6. Furthermore, use of dedicated satellites to monitor earthquake precursors from space (Dobrovolsky, 1971) has been defined for a centralized prepare zone; not for a wide area. As the target zone is a circle of radius $5 \mathrm{~km}$ and the monitoring station located at the center of this area, the uncertainly parameter is considered $5 \mathrm{~km}$. 
Design and Development of an Earthquake Warning System Module using Electronic Sensor for Tilt Identification and Low Frequency Sensing Analysis

\section{Earthquake Preparation Zone}

The concept of earthquake preparation zone was developed by different scientists, Dobrovolsky(1971), Keilis-Borok and Kossobokov(1990) and Bowman et al.(1998). This is an area where the local deformations and their effects caused by the future earthquake are observed. For example, the deformations cause strain accumulation in the crust which can be measured by strain gauges and tilt meters (Yoshihisa et al., 2002) as well as by GPS (Kostoglodov,2003), predict formation of cracks within the preparation zone and this will result in changes in seismic wave velocity, density, electric resistivity, ground water level(Khalilov, 2005). All these changes can be monitored experimentally. The ground surface projection of the spherical earthquake projection zone is given by Dobrovolsky et al., 1971 as $\rho=10^{0.434} \mathrm{M} \mathrm{km}$ or $\log \rho=0.434 \mathrm{M}$.

[1] Increase of radon concentration in air.

[2] Increase of electric field near ground level.

[3] Increase of ground temperature.

[4] Decrease of relative humidity of air.

Continuous Monitoring of the above precursors and their real-time recording at a Central Station have been planned at CES. This will be more effective and advantageous than random measurements taken now and then elsewhere so far. Also, for the non-circle target zone, it is better to fit a circle to the range of study area and then finding this value. Afterwards, for each disturbed station (stations which show anomaly), a circle of radius $\mathrm{R}=$ $\mathrm{R}^{\prime}+\mathrm{dr}$ has been drawn which called 'investigation circles' (In.Cs). After drawing the In.Cs, 'Expectation circle' (Ex.C) is defined as a circle of radius $\mathrm{R}$ which its center being within the target zone And finally, the springs which located within the Ex.C are called 'Expectation Springs' and denote by Ex.Ss.

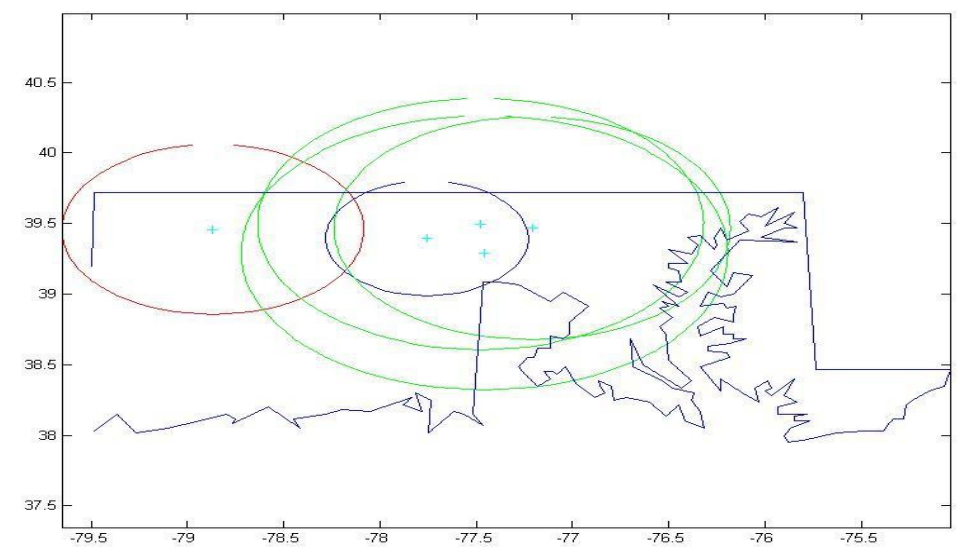

Fig5. Sensing Range Identification based on Inner and Outer Expectation Circles

For Early Warning based on WSNs, the stations (the seismological term) or nodes (networking term), are deployed in the city itself, that is, where the damaging is to be expected. This approach is called an On-site system - in contrast to Front-detection systems, where the stations would be placed near to the hot springs. $D / R$ ratio is described which $D$ is the strain radius and $R$ is distance between monitoring station and earthquake epicenter $(\mathrm{km})$. Radius of the zone within which precursory phenomena may be manifested (so-called strain radius R in Dobrovolsky equation). First of all, the "target zone" has been defined as the study area which constituted from porous cracked saturated rocks and with high capacity of cracks growth during increasing tectonic stress. In this distinctive zone, a radon monitoring measurement in soil and groundwater has been implemented (radon precursory study in soil and groundwater is quite difference in measurement methods, 
Design and Development of an Earthquake Warning System Module using Electronic Sensor for Tilt Identification and Low Frequency Sensing Analysis

but not in interpretation with seismic events). if any anomaly has been observed in two or more than two monitoring stations, the distance between the farthest of them and the center of target zone (R') has been measured. In this study - and by most scientists-an anomaly defined as radon concentration spike crossing $-\mathrm{x}+\mathrm{dr}$ where ${ }^{-} \mathrm{x}$ is the average and $d r$, the standard deviation. Then several kilometers according to vastness of target zone must be added to this measured value as "uncertainly parameter" (dr). Because, Dobrovolsky equation has been defined for a centralized prepare zone; not for a wide area. For example, if the target zone is a circle of radius $5 \mathrm{~km}$ and the monitoring station located at the center of this area, the uncertainly parameter is considered $5 \mathrm{~km}$. Also, for the non-circle target zone, it is better to fit a circle to the range of study area and then finding this value. Afterwards, for each disturbed station (stations which show anomaly), a circle of radius $\mathrm{R}=\mathrm{R}$ ' $+\mathrm{dr}$ has been drawn which called 'investigation circles' (In.Cs) as shown in Figure 5. After drawing the In.Cs, 'Expectation circle' (Ex.C) is defined as a circle of radius $\mathrm{R}$ which its center being within the target zone And finally, the springs which located within the Ex.C are called 'Expectation Springs' and denote by Ex.Ss. Proposed algorithm establishes a new high accuracy method to obtain the range of location and magnitude of a coming earthquake for a target zone. In the first step, we assume that between these hotsprings, three of them indicate anomaly in radon concentration (for example A1, A2 and A3). In the second step, according to proposed algorithm distance between $\mathrm{A} 3$ and center of city X-which introduced as target zone-is about 84.6 $\mathrm{km}(\mathrm{R} 0)$ which is more than the other distances. So, we nominate the A3 as the farthest station which anomaly has been observed. In third step, by considering the vastness of Xth city, it is inferable that $\mathrm{dr}=10 \mathrm{~km}$ should be added to R0. R= R0+ dr= 84:6+10=94:6 km. In the next step, we draw a circle of radius $94.6 \mathrm{~km}$ to the center of Xth city as Ex.C (red circle). Between the all selected hot-springs, four of them located within this circle: A1, A2, $\mathrm{A} 3$ and A4. Then we draw four circles of radius $\mathrm{R}$ in the center of these hot-springs as In.Cs. The area of interface between these four In.Cs becomes 1,477 km2 which illustrate the location of coming earthquake. Also, between the undisturbed hot-springs, Station $C$ is the nearest station to Xth city which lies outside of Ex.C. Therefore, according to Table 2 and considering dr $=10 \mathrm{~km}$ for $\mathrm{X}$-as described before-we have: $\mathrm{L}=\mathrm{L} 0+\mathrm{dr}=109: 2+10=$ 119:2 km. The capability of proposed algorithm to implementation in all kind of geological structures because Dobrovolsky equation has been examined in different structures whereby capability of proposed algorithm to design various continuous radon monitoring networks in soil and groundwater to predict earthquakes. Proposed algorithm can be used for all geochemical precursors to predict earthquake. Have some sensing range and complete coverage of detected area D if Ai denotes the size of area covered by ith placed sensor node. Minimum number of working nodes is equivalent of minimum of size of overlap region and can be calculated as shown below.

Our research is based on boolean sensing model where sensor node can detect only events that are within certain range of it for a circular article. Let $r$ denote the sensing range of each node, and $l$ denote the radio range. It has been proved that if the radio range is at least twice the sensing range, complete coverage of a convex area implies connectivity among the working set of nodes. Assuming that $\mathrm{n}$ sensor nodes are randomly distributed over radius $\mathrm{R}$ region. Set of $\{\mathrm{S} 1, \mathrm{~S} 2, \mathrm{~S} 3, \ldots\}$, for all1 $\leq \mathrm{i} \leq \mathrm{n}$. let Ai denote the size of area that is covered by the $\mathrm{i}$ th placed sensor node, A denote the size of the whole detected region $D A=\pi R 2_{0}$ The multi-coverage problem can be described that seek a subset $S^{\prime}$, making maximum coverage fraction $R\left(S^{\prime}\right) S$ and minimum number of working sensor nodes $S^{\prime}$.Capability of proposed algorithm to design various continuous radon monitoring networks in soil and groundwater to predict earthquakes. Anomalies in radon concentration have been observed in only nine of hot-springs. Proposed algorithm can be used for all geochemical precursors to predict earthquake .using minimum number of nodes for this analysis is a task which all need to take care of regional coverage, point coverage and barrier coverage. The probability of any node distributed in sub-region D', D' D , is related only with the size of $D^{\prime}$, so $p=A D^{`} / A D$. Therefore, for all $1 \leq i \leq n$, sub-object function of coverage fraction is 
Design and Development of an Earthquake Warning System Module using Electronic Sensor for Tilt Identification and Low Frequency Sensing Analysis

$\mathrm{f}(\mathrm{x})=\mathrm{R}\left(\mathrm{S}^{\prime}\right)=\mathrm{A} \mathrm{D}^{\prime} / \mathrm{AD}$ ' in which $\mathrm{D}^{\prime} \mathrm{A}$ is the size of the region that is covered by $\mathrm{S}^{\prime}$. Thus we have ECQ=[. The proportion of the number of working nodes $S^{\prime}$, to the total number of nodes $S$, is the sub-object function of the number of working nodes. W1AD'/AD + w2(1-S'/S). w1, w2 are the weights of sub-object function. p(x,y) $€$ $D$, theneighbor of it definite as follows: $K(x, y)=\left\{\forall \in\left(x^{\prime}, y^{\prime}\right) \in D \mid\left(\left(x^{\prime}-x\right)^{2} \mid+\left(y^{\prime}-y\right)^{2} \leq r^{2}\right)\right\}$. Let Ai denote the size of area which is covered by i th placed sensor node, and Xi denote the extra 1- coverage area contributed by the $i$ th placed sensor. $E[A i]=E[A]=1 / A$

Let $\mathrm{Gi}=\mathrm{Xi} / \mathrm{Ai}$ be the proportion of the extra coverage area contributed by the $\mathrm{i}$ th placed sensor to its node coverage. We have E C1 $=\mathrm{E} \mathrm{X1}=\mathrm{E}$ A and $\mathrm{C} \mathrm{i}=\mathrm{Ci}-1+\mathrm{X}$ for all $\mathrm{i}, 2 \leq \mathrm{i} \leq \mathrm{n}$

$\mathrm{E}[\mathrm{Ci}]=\mathrm{E}[\mathrm{Ci}-1]+\mathrm{E}[\mathrm{Xi}]$

$\mathrm{E}[\mathrm{Xi}]=\mathrm{E}[\mathrm{Gi}] * \mathrm{E}[\mathrm{Ai}]$

As sensor nodes are uniformly distributed, Gi is expected to be the proportion of the uncovered area to the whole deployment area.

$\mathrm{E}[\mathrm{Gi}]=\mathrm{A}-\mathrm{E}[\mathrm{Ci}-1] / \mathrm{A}$

$\mathrm{E}[\mathrm{Ci}]=\mathrm{E}[\mathrm{Ci}-1]+\mathrm{A}-\mathrm{E}[\mathrm{Ci}-1] / \mathrm{A}^{*} \mathrm{E}[\mathrm{Ai}]$

which $\mathrm{Ai}^{\mathrm{j}}$ denote the size of $\mathrm{j}$-covered area after i sensor nodes have been placed in $\mathrm{j}$

Yi denote the extra area to the sensor region of $\mathrm{i}$ th placed sensor node to the size of $\mathrm{j}$-covered region, $\mathrm{Pi}^{\mathrm{j}}$ is the proportion of $\mathrm{Yi}^{\mathrm{j}}$ to Ai . According to (5) and (6), we have Reducing the overlapping area to reduce the number of working nodes, the lifetime of wireless sensor networks can be prolonged. Since E[A]/A is the probability of link occurrence $\mathrm{p}, \mathrm{A}=\pi \mathrm{r}^{2}$, and $\mathrm{E}[\mathrm{Cn}]$ expressed as follows: we can obtain the result to k-coverage problem. For all $0 \leq \mathrm{i} \leq \mathrm{n}, 0 \leq \mathrm{j} \leq \mathrm{k}$, and $\mathrm{i}$.

$E[C n]=\left[1-\left(1-r^{2} / R^{2}\right)^{n}\right] A$

The equation will help us to analyze network life vs number of nodes with full coverage R and initial amount of energy of each node for considering a cellular pattern of k range

$0 \leq \mathrm{i} \leq \mathrm{n}, 0 \leq \mathrm{j} \leq \mathrm{k}$ and $\mathrm{i} \mathrm{j}$.

$\mathrm{E}\left[\mathrm{Ai}{ }^{\mathrm{j}}\right]=\mathrm{E}\left[\mathrm{Ai}-1^{\mathrm{j}}\right]+\mathrm{E}\left[\mathrm{Yi}^{\mathrm{i}}\right]$

$\mathrm{E}\left[\mathrm{Yi}^{\mathrm{j}}\right]=\mathrm{E}\left[\mathrm{Pi}^{\mathrm{j}}\right]+\mathrm{E}[\mathrm{A}]$

Where by Ai ${ }^{j}$ is size of the $\mathrm{j}$ covered area after $\mathrm{i}$ sensor nodes has placed; $\mathrm{Yi}^{\mathrm{j}}{ }^{\mathrm{i}}$ is extra area to sensor region of $\mathrm{i}$ th placed sensor node to the $\mathrm{j}$ covered region. $\mathrm{Pi}^{\mathrm{j}}$ is proportion of $\mathrm{Yi}^{\mathrm{j}}$ to $\mathrm{Ai}$.

$E\left[\mathrm{Pi}^{\mathrm{j}}\right]=\mathrm{E}\left[\mathrm{Yi}^{\mathrm{j}}\right] / \mathrm{E}[\mathrm{A}]=\mathrm{E}\left[\mathrm{A}^{\mathrm{j}-1} \mathrm{i}-1\right]-\mathrm{E}\left[\mathrm{A}^{\mathrm{j}-1}\right] / \mathrm{Ai} \quad 0 \leq \mathrm{l} \leq \mathrm{i}-\mathrm{j}$

$E\left[A i{ }^{j}\right]=(1-p) E\left[A i-1^{j}\right]+p E\left[A i-1^{j-1}\right]$.

Lemma 1:if Si $€\{\mathrm{~S} 1, \mathrm{~S} 2, . . \mathrm{Sn}\}$

Have some sensing range and complete coverage of detected area D if Ai denotes the size of area covered by ith placed sensor node. Minimum number of working nodes is equivalent of minimum of size of overlap region for $A^{`}=\|$ D size of area covered by ith node for degree of overlapping coverage at any point where $H(x)=\operatorname{If} x \operatorname{IR}(x)=1$ or else $\operatorname{IR}(x)=0$; And if $x \in \operatorname{Ii}(x)=1$ or else $\operatorname{Ii}(x)=0 ; L=n|A i|-|D|$. By reducing the overlapping area to reduce the number of working nodes the lifetime of sensor networks can be prolonged. Consider a deployment region of size A. Let a denote the size of nodes sensing region outside the detected area R", P denote the probability of $n$ sensor nodes coverage. Given a fixed sensory range such that the expected node coverage is $\mathrm{E}[\mathrm{N}]$, the number 
Design and Development of an Earthquake Warning System Module using Electronic Sensor for Tilt Identification and Low Frequency Sensing Analysis

of sensor nodes is suffice for this inequality. As the proportion of the sensing range of nodes to the range of de deployment area is known, the number of nodes needed to placed to achieve the multi-coverage fraction can be estimated that achieved the coverage and connectivity requirement.

\begin{tabular}{ll}
$\log (1-\mathrm{P})$ & $<\mathrm{n}<\log (1-\mathrm{P})$ \\
\hline $\log (1-\mathrm{E}[\mathrm{N}] / \mathrm{A})$ & $\log (1-\mathrm{E}[\mathrm{N}] / \mathrm{A}+\mathrm{a})$
\end{tabular}

Size of the sensing is $\pi r^{2}$ ignoring the bordering effects probability of each point $p(x, y) \in D$ covered by at least one node is equal to the probability of the node distributed in the neighborhood.

The probability of one node sensing whole area is $\pi r^{2} / A$

Probability of two nodes $\mathrm{P} 2=\mathrm{P}(\mathrm{A})+\mathrm{P}(\mathrm{B})-\mathrm{P}(\mathrm{A})$

$$
\begin{aligned}
& =\mathrm{p}+\mathrm{p}-\left(\mathrm{p}^{*} \mathrm{p}\right) \\
& =2 \mathrm{p}-\mathrm{p} 2
\end{aligned}
$$

Probability of three nodes $\mathrm{P} 3=\mathrm{P} 2+\mathrm{p}-\mathrm{P} 2 * \mathrm{p}$

$$
\begin{aligned}
& =2 p-p 2+p-(2 p-p 2)^{*} p \\
& =1-(1-p) 3
\end{aligned}
$$

By mathematical induction we can deduce that $\mathrm{p}=1-(1-\mathrm{p})^{\mathrm{n}}$

$N=\log (1-p) /\left(1-\pi r^{2} / A\right)=\log (1-p) / \log \left(1-\pi r^{2} / A\right)$

$\mathrm{n}>\log (1-\mathrm{P}) / \log \left(1-\pi \mathrm{r}^{2} / \mathrm{A}\right)$

This shows that proportion of sensing range to range of deployment area is known the number of nodes needed to be placed to achieve multi-coverage fraction can be estimated that achieved coverage and connectivity requirement.

\section{CONCLUSION}

The design of the device is a representation of an innovative approach in construction of an earthquake warning and alert system. The system uses two different subsystems and detects the change in the strain pattern by the subsystems. All sensors used are readily available and cheap thus making it a user friendly and affordable product. The Radon monitoring stations should be deployed in quite stable rocks within blocks of the slowest "secular motion" selected from three or four years of GPS data. The LM324 is found to have very poor input and output range especially when working on a single supply and would require two or more Radon detection units. Secondly, the low frequency characteristics can be changed based on the RC time constant in the circuits involved. Proposed algorithm establishes a new high accuracy method to obtain the range of location and magnitude of a coming earthquake for a target zone. Increasing the accuracy of results could be obtained with increasing the number of radon monitoring stations.

\section{REFERENCES}

1. Bowman, D.D., Ouillon, G, Sammis, C.G., Sornette, A. and Sornette, D. 1998. An observation test of the critical earthquake concept. J. Geophys. Res. 103:24359-24372.

2. Dobrovolsky IP, Zubkov SI and Miachkin VI (1979) Estimation of the size of earthquake preparation zones. Pure Appl Geophys 117(5):1025-1044. doi:10.1007/bf00876083. 
Design and Development of an Earthquake Warning System Module using Electronic Sensor for Tilt Identification and Low Frequency Sensing Analysis

3. Dutta,P.K.(2017) Earthquake Alarm Detector Microcontroller based Circuit for issuing Warning for vibration in Steel Foundations, International Journal of Mechatronics, Electrical and Computer Technology, 7(26), Oct. 2017, PP. 3582-3594, doi: ijmec/10.225147

4. Dutta, P. K., Naskar, M. K. and Mishra, O. P. (2012a) Test of strain behavior model with Radon anomaly in earthquake prone zones. Himalayan Geology, 33(1), 23-28.

5. Dutta, P. K., Naskar, M. K. and Mishra, O. P. (2012b) Test of Strain Behavior Model with Radon Anomaly in Seismogenic Area: A Bayesian Melding Approach. International Journal of Geosciences, 3(1).

6. Dutta, P. K., Mishra, O. P. and Naskar, M. K. (2012c) Decision analysis for earthquake prediction methodologies: fuzzy inference algorithm for trust. International Journal of Computer Applications, 45(4).

7. Dutta, P.K., Mishra, O.P. and Naskar M.K. (2013a). Improving Situational Awareness for Precursory Data Classification using Attribute Rough Set Reduction Approach. International Journal of Information Technology and Computer Science, 5(12).

8. Dutta, P. K., Naskar, M. K. and Mishra, O. P. (2013b) Impact of two-level fuzzy cluster head selection model for wireless sensor network: An Energy efficient approach in remote monitoring scenarios. arXiv preprint arXiv:1308.0690.

9. Keilis-Borok, V.I. and Kossobokov, V.G. 1990. Premonitory activation of earthquake flow, Algorithm, M8. Phy. Earth planet Inter. 61:73-83.

10. King, C. Y. (1991) Gas-Geochemical Approaches to Earthquake Prediction (Isotopic and geochemical precursors of earthquakes and volcanic eruptions. In: Proceedings of an Advisory Group Meeting .held in Vienna, 9-12,September 1991.

11. Khalilov, E.N. 2005. Method for recording the low-frequency gravity waves and device for the measurement thereof. Patent of PCT. WO 2005/003818 A1, Geneva, 13.01.

12. Kostoglodov, V., Larson, K. Singh, S.K., Lowry, A., Santiago, J.A., Franso S.I. and Bilham, R. 2003. A large silent earthquake in the Guerrero seismic gap, Mexico. Geophys. Res. Lett. 30:1807.

13. Kozlova, I.A. and Yurkov, A.K., 2005. Soil-gas radon-222 monitoring: Methodological issues. Uralskii Geofizicheskii Vestnik, No. 7, 31-34.

14. Mishra O.P. (2007) Seismo-geophysical Precursors: Success and failure in earthquake prediction. In: National Workshop on Earthquake Precursors, Delhi on June 28-29, 2007, organized by Ministry of Earth Sciences, Govt. of India.

15. Outkin, V.I. (2000) Space-time radon monitoring as a basis for medium-term earthquake prediction. Uralskii Geofizicheskii Vestnik, No. 1,101-106.

16. Outkin, V. I., Yurkov, A. K. and Kosyakin, I. I. (2006) Radon as the determined indicator of the natural and technological geodynamic processes. In: Saint Petersburg 2006.

17. Outkin, V. I. and Yurkov, A. K. (2010) Radon as a tracer of tectonic movements. Russian Geology and Geophysics, 51(2), 220-227. 
Design and Development of an Earthquake Warning System Module using Electronic Sensor for Tilt Identification and Low Frequency Sensing Analysis

18. Outkin, V. I., Dutta, P. K., Mishra, O. P., Naskar, M. K., Kozlova, I. A. and Yurkov, A. K. (2013). Radon as a Early Warning Tool in Tectonic Monitoring Environments Analyzing Data Behavior. Journal of Geodetic Science, 3(3), 203-208.

19. Outkin, V. I., Kozlova, I. A., Yurkov, A. K., Dutta, P. K., Mishra, O. P. and Naskar, M. K. In:Radon monitoring as a possible indicator of tectonic events in SAP: // Earth Sciences and Geography, 11, 2121-2126, 2012 (In Russian).

20. Schulz, C.H., Sykes, L.R. and Agarwal, Y.P. 1973, Earthquake Prediction: A Physical Basis. Science181:803-810.

21. Srivastava, H. N. (1983) Forecasting earthquakes. National Book Trust.

22. Yoshihisa, I, Yoji, K. and Takashi, T. 2002. Large earthquakes initiated by the acceleration of slips on the download extensions of seismogenic faults. Earth Planet. Sci. Lett. 202:337-343.

Citation: Pushan Kumar Dutta, "Design and Development of an Earthquake Warning System Module using Electronic Sensor for Tilt Identification and Low Frequency Sensing Analysis", American Research Journal of Earth Science, vol 1, no. 1, pp. 44-55.

Copyright (C) Pushan Kumar Dutta, This is an open access article distributed under the Creative Commons Attribution License, which permits unrestricted use, distribution, and reproduction in any medium, provided the original work is properly cited. 